\title{
Reliability and long-term stability of the mounted silicon for precision measurements
}

\author{
Thomas Frank, Andrea Cyriax, Andre Grün, Manuel Kermann, Thomas Ortlepp \\ CiS Forschungsinstitut für Mikrosensorik GmbH, Konrad-Zuse-Str. 14, 99099 Erfurt, Germany \\ tfrank@cismst.de
}

\begin{abstract}
Silicon strain gauges have a much higher gauge factor than metal foil strips. These can replace piezoresistive thin-film resistors and thus create a cost-effective and high-quality sensor. The technical challenge lies in the long-term stable connection between the silicon strain gauge and the steel spring body. Preferably, sealing glass paste is used. Due to the high processing temperature of approx. $450^{\circ}$ $\mathrm{C}$ and the different coefficients of thermal expansion, high mechanical stresses are induced. To ensure that this stress does not lead to failure, very precise process control is necessary. Investigations were carried out on different material savings, long-term thermal interferences and Air to Air Thermal Shock Testing.
\end{abstract}

Key words: long-term stability, reliability, silicon, strain gauges, stress, piezoresistive, Air to Air thermal shock testing, sealing glass paste, pressure sensor

\section{Introduction}

In order to measure basic mechanical quantities such as pressure, stress, torque, acceleration and mass, it is necessary to measure the applied force. The most commonly used measuring principle is based on the piezoresistive effect. It is used by connecting four resistors to a Wheatstone bridge.

In macro applications today, foil-based strain gauges with metallic conductor lines consisting of primarily copper nickel manganese alloys (brand name constantan) are being used [1]. This alloy is characterized by an excellent low temperature coefficient of resistance approximately $1 \mathrm{E}-5 \mathrm{~K}^{-1}$. Compared to pure metals (copper, silver approx $\approx 4 \mathrm{E}-3 \mathrm{~K}^{-1}$ ) it is lower by a factor of 400 [1]. Many experimental stress and strain analyses are possible due to the simple usage of foil strain gauges. Measurement principles based on the piezoresistive effect are also used in microsystems technology. In the MEMS technology, however, silicon-based measuring resistors are used.

Here, the piezoresistive resistors are monolithically integrated directly into the silicon component by diffusion or implantation. The main application is found in pressure sensors. Compared with the metal strain gauges the semiconductor integrated resistors have a higher gauge factor and a significantly higher long-term stability. A major advantage of using single-crystal material is the lack of dislocations and grain boundaries. In ductile metal, these lead to increased uncertainty as a result of permanent plastic deformation (plastic flow). In the case of monolithic silicon sensors two doping variations are common. In most commonly used method the resistive elements can be realized in the n-type base material by doping with a 3-value element (typically boron). In this case, the piezoresistive coefficients for the lateral and longitudinal loads are nearly the same with different signs. Therefore, a bridge can be constructed by mounting two resistors parallel and two resistors perpendicular to the applied stress or strain. This allows a high degree of miniaturization.

The silicon-strain gauges so have some advantages over the metal strain gauges but also some disadvantages. The main advantages of metal strain gauges are mechanical handling and low Temperature coefficient of reactivity due to the good thermal adaptation to the DUT.

One advantage of the monocrystalline strain gauge is determined by the high gauge factor. The silicon gauge factor is about 100 whereas the metal strain gauge is approx 2 - 3. A further advantage is the miniaturization, an area of 100 $\mu \mathrm{m} \times 100 \mu \mathrm{m}$ is sufficient for a full Wheatstone bridge. High demands are placed on the overall geometry and packaging to take advantage of these benefits.

\section{Structure of silicon strain gauge}

Silicon strain gauge is based on the $n$-doped (phosphorous) silicon wafer, $<100>$ orientation, with a resistivity of $R=3 \ldots 5 \Omega \mathrm{cm}$. With the 
help of MEMS technologies, the strain gauge can be produced. In Fig. 2 the layout is shown. The implantation parameters are configured for a sheet resistance of the piezoresistive resistance of about $200 \Omega / \mathrm{Qu}$ with a temperature coefficient of about $0.8 \% / \mathrm{K}$. The piezoresistive resistors are connected by highly-implanted leads. Around the diffused resistors and leads there is an $\mathrm{n++}$ - doped guard ring. This serves to suppress parasitic current paths. In Fig. 1, the circuit of the measuring bridge is shown. The piezoresistive coefficients for the longitudinal and transverse effect are similar in magnitude

$$
\begin{aligned}
& \pi_{\mathrm{L}(100)}=71.810^{-11} \mathrm{~Pa}^{-1}, \\
& \pi_{\mathrm{L}(100)}=-66.310^{-11} \mathrm{~Pa}^{-1},
\end{aligned}
$$

but have opposite signs, thereby it is possible to build a concentrated full-bridge on a chip. It is also possible to build a spread full bridge with individual resistors.

The footprint of the silicon strain gauge is 500 $\mu \mathrm{m} \times 500 \mu \mathrm{m}$. For the different applications, the sensors can be thinned down to $5 \mu \mathrm{m}$.

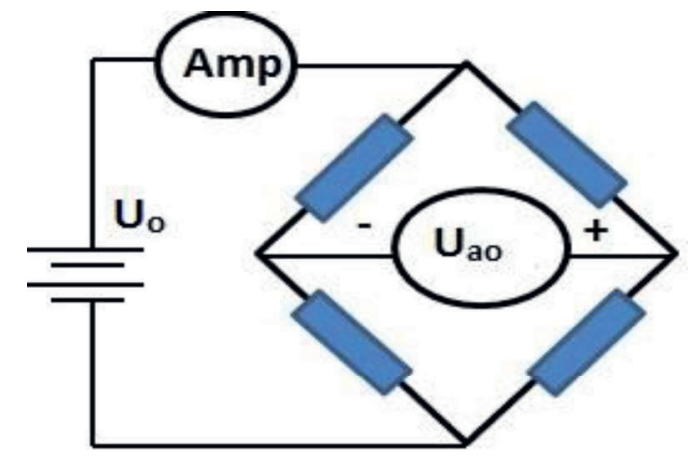

Fig. 1: Complete measuring bridge with two resistors for the longitudinal and transverse effect

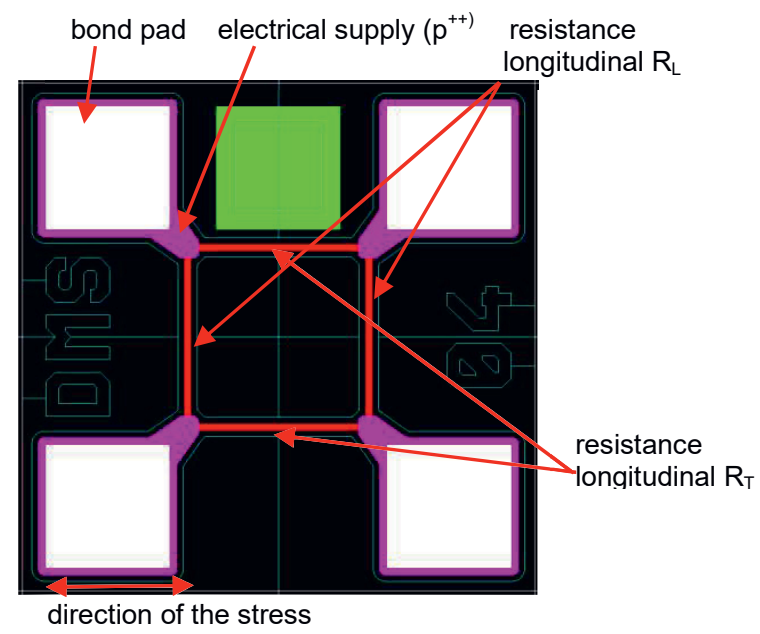

Fig. 2: Design of the silicon strain gauge, the footprint is $500 \mu m \times 500 \mu m$

\section{Criteria for the design of the silicon strain gauge}

The silicon strain gauge is mounted on different spring bodies by means of glass frit, the processing temperature is about $450{ }^{\circ} \mathrm{C}$. Due to the high differences in thermal expansion between metallic spring bodies and the silicon, strong compressive stresses are imbedded in the silicon strain gauges. These, of course, also affect the measuring resistors, which are connected to a measuring bridge. The measuring bridge compensates for the strain almost completely if the conditions on all measuring resistors are identical. This is achieved by a completely symmetrical design.

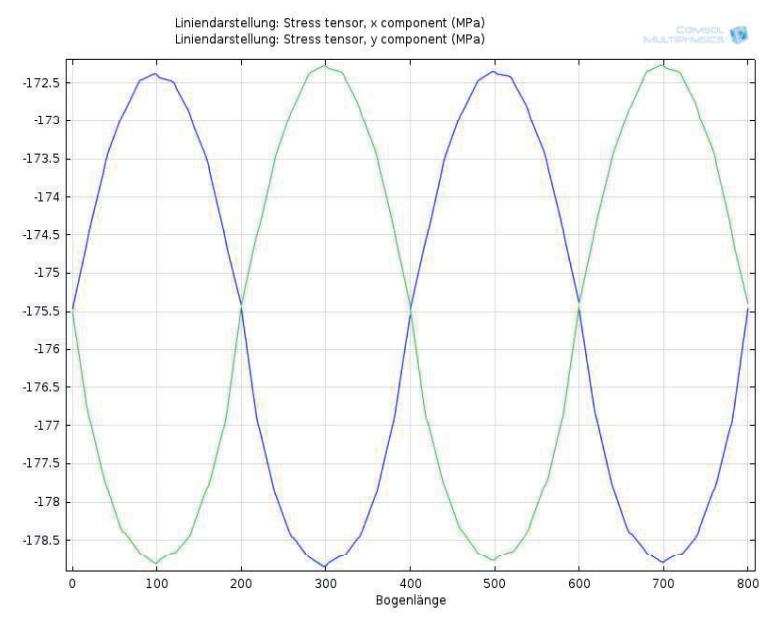

Fig. 3: Square chip geometry, see (Fig. 2), stress at the four measuring resistors

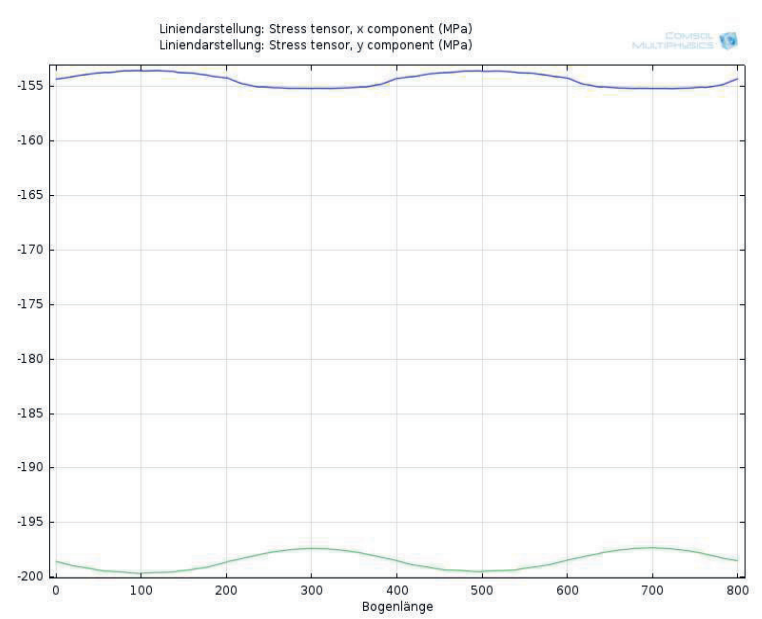

Fig. 4: Rectangular chip geometry, stress on the four measuring resistors

Fig. 3 shows the simulated distribution of the mechanical stress on the four measuring resistors of the silicone strain gauge shown in. The temperature difference between the transformation point of the glass solder and the working temperature is $250 \mathrm{~K}$. The loads are 
consistently compressive stresses and uniformly distributed. In the case of the rectangular chip, Fig. 4, this is not the case, which leads to high offset values. An uneven thickness of the glass solder in the gap would have the same effect. The measuring bridge cannot compensate for this.

\section{Criteria for a good construction}

For the use of the silicone strain gage, these are joined to spring bodies. These spring bodies can be bending plates for pressure measurement or a spring guide on the basis of a four-bar linkage for force measurement. High demands are placed on the connection. In particular, this must be long-term stable. This means that the mechanical stress is transferred from the spring body to the silicone strain gauge without loss. Temperature fluctuations must not cause hysteresis. The creep due to the high mechanical stress is to be excluded. Aluminum, titanium and steel are suitable as materials for the spring body. A secure connection that satisfies the requirements can provide a glass solder connection [2].
The average offset of the measuring bridges of the tested Silicon Strain Gauge is $1.46 \mathrm{mV} / \mathrm{V}$ before assembly, the reference temperature is $30{ }^{\circ} \mathrm{C}$. This is a good value for a measuring span of $100 \mathrm{mV} / \mathrm{V}$. The Silicon Strain Gauge was joined with glass solder to various test specimens, V2A, spring steel 1.4310 , titanium and aluminum. The problem with joining with glass solder is the high processing temperature combined with the difference in thermal expansion coefficient. These lead to extreme thermally induced mechanical stresses. A nonuniform mounting, thickness of the glass solder or the outer edge around the chip lead to a temperature-dependent detuning of the measuring bridge to an increased offset and to a high temperature gradient of the offset.

The Tab. 1 shows the bridge offset and the temperature coefficient of the bridge offset for different material pairings. The "manual work" causes fluctuations in the glass solder thickness. A chip which is not mounted parallel to the bending plate leads to uneven mechanical stress and thus to an increased offset.

Tab. 1: Bridge offset and temperature coefficient of the bridge offset

\begin{tabular}{|l|l|l|l|l|l|}
\hline & $\begin{array}{l}\text { Coefficient of thermal } \\
\text { expansion } \\
10^{-6} \mathrm{~K}^{-1}\end{array}$ & $\mathrm{U}_{\text {offset } 30^{\circ} \mathrm{C}}$ & $\begin{array}{l}\mathrm{U}_{\text {offset } 30^{\circ} \mathrm{C}} \\
(\text { minimal) }\end{array}$ & $\begin{array}{l}\text { Temperature } \\
\text { gradient of the } \\
\text { offset }\end{array}$ & $\begin{array}{l}\text { Temperature } \\
\text { gradient of the } \\
\text { offset (minimal) }\end{array}$ \\
\hline Silicon Chip & 2.3 & $\mathrm{mV} / \mathrm{V}$ & $\mathrm{mV} / \mathrm{V}$ & $\mu \mathrm{V} / \mathrm{VK}$ & \\
\hline V2A & 16.0 & 7.95 & 0.23 & 2.1 & \\
\hline Titanium & 8.6 & 4.48 & 0.54 & 41.5 & 5.9 \\
\hline Aluminium & 23.1 & 32.9 & 21.8 & 13.3 & 6.73 \\
\hline $\begin{array}{l}\text { Spring steel } \\
1.4310\end{array}$ & 16.0 & 14.3 & 12.9 & 87.2 & 119 \\
\hline
\end{tabular}

\section{Air to Air Thermal Shock Testing}

In order to assess the reliability of the connection, a temperature shock test air / air was performed. The basic body used was aluminum. Due to the large differences in the Coefficient of thermal expansion, the greatest mechanical stresses are to be expected. The Fig. 5 to 8 show a silicon strain gauge, mounted with glass solder on aluminum after a temperature change (1000 times $-40{ }^{\circ} \mathrm{C}$ to + $\left.135^{\circ} \mathrm{C}\right)$. The pictures show the integrity. No damage could be found.

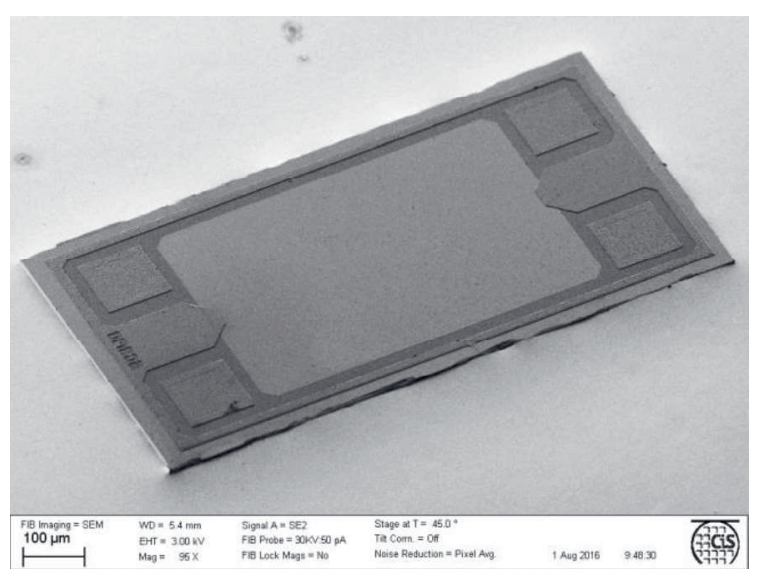

Fig. 5: SEM of connection with glass frit 


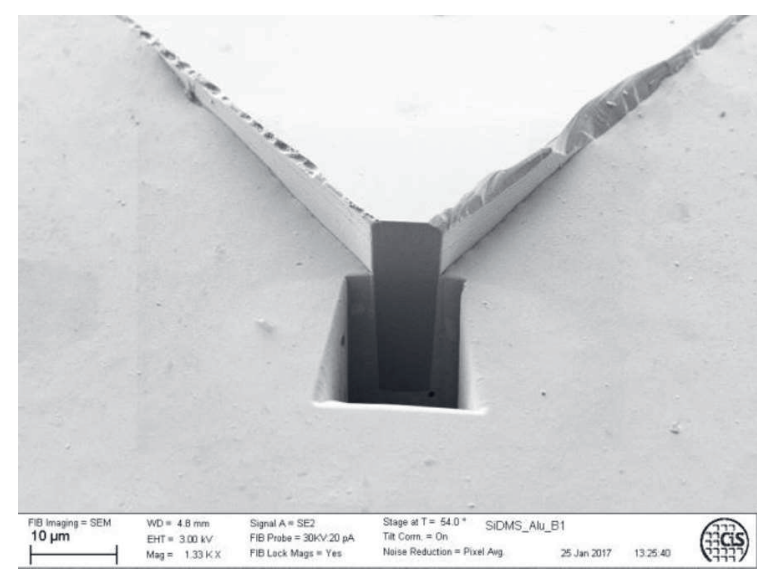

Fig. 6: SEM of connection with glass frit, focused ion beam preparation of the corner

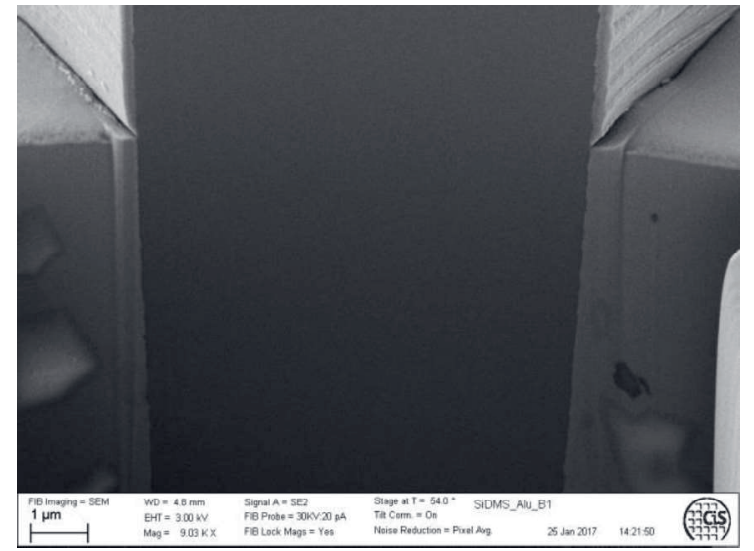

Fig. 7: SEM of connection with glass frit, focused ion beam preparation of the corner, detail

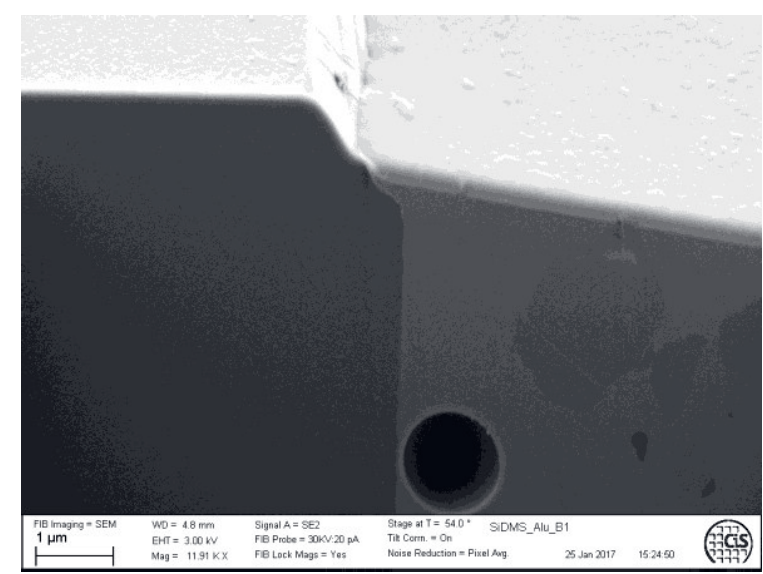

Fig. 8: SEM of connection with glass frit, focused ion beam preparation of the edge, detail

\section{Long-term stability of the offset}

There may be various causes for changing the offset with time and at elevated temperature. The dependence of the offset on the time at high temperature is investigated. 7 cycles were run, with $2 \mathrm{~h}$ at $30^{\circ} \mathrm{C}$ and $22 \mathrm{~h}$ at $120^{\circ} \mathrm{C}$. It can be seen that the measuring signal is stable after a running-in time of $40 \mathrm{~h}$.
Fig. 9 and Fig. 10 show the first results of a long-term examination. The cause of the temporal change of the offset can be manifold and is still to be examined.

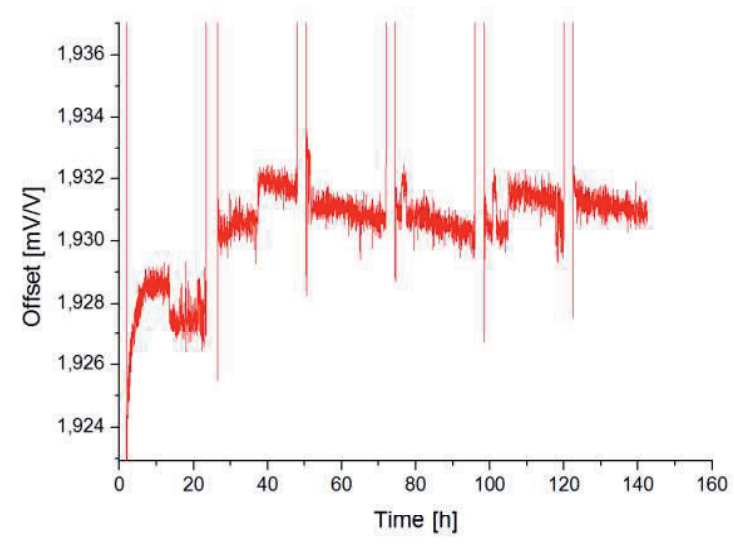

Fig. 9: Running at $120{ }^{\circ} \mathrm{C} / 30^{\circ} \mathrm{C}$ cycles, Silicon on Titanium and Steel, Steel: The complete cycle is shown, the range for $120^{\circ} \mathrm{C}$ is shown enlarged

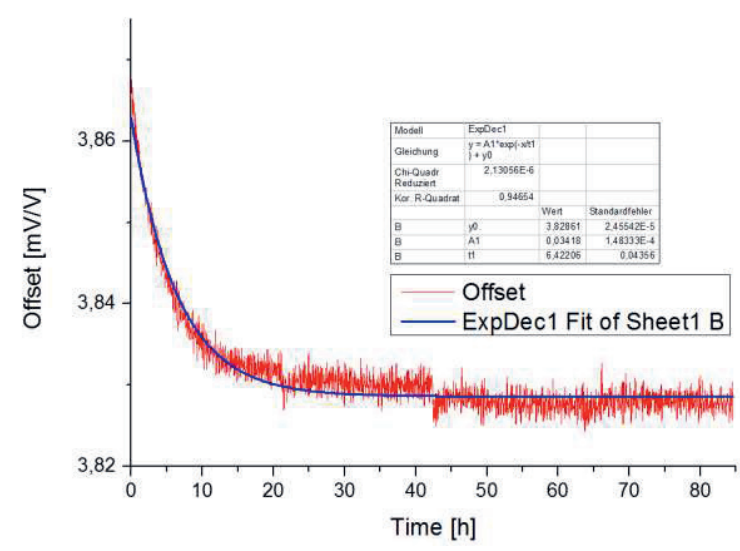

Fig. 10: Titanium: It shows only the $120^{\circ} \mathrm{C}$ cycle

\section{Acknowledgment}

We thank the Bundesministerium für Wirtschaft und Energie (BMWi) for the support of these projects SiStGAP (MF150091) and Smarter Si (ICT-02-2014) financially.

\section{Reference}

[1] Rausch, Jacqueline Franziska Katharina. Entwicklung und Anwendung miniaturisierter piezoresistiver Dehnungsmesselemente. (2012). Rausch, J. F. K.

[2] T. Frank, M. Khatri, M. Fiedler, A. Gruen, M. Kermann, A. Cyriax, T. Ortlepp, Miniaturized silicon strain gauge elements to accurately measure mechanical quantities, Germany, AMA Conferences 2015, Germany, 19. - 21.5.2015 